\title{
Selective Incorporation of Difluoromethylene Moieties into Arenes Assisted by Transition Metals
}

\author{
Bing Gao, Chuanfa Ni, and Jinbo Hu*
}

\begin{abstract}
Fluorinated compounds are of significant importance in various fields due to their unique chemical, physical, and biological properties. Accordingly, the incorporation of fluorine atom(s) or fluorine-containing functionalities into organic molecules has received considerable attention. For decades, extensive reports and reviews mainly focused on the fluorination and perfluoroalkylation (especially trifluoromethylation) whereas the preparation of partially fluorinated compounds was less developed. Difluoromethylated arenes and their derivatives $\left(\mathrm{ArCF}_{2} \mathrm{R}, \mathrm{R} \neq \mathrm{F}, \mathrm{R}_{\mathrm{f}}, \mathrm{H}\right)$ have been found to be as important in pharmaceuticals as trifluoromethylated arenes. However, it is only recently that these compounds have experienced a revival of interest from synthetic chemists. The direct construction of carbon( $\left(\mathrm{sp}^{2}\right)$-carbon( $\left(\mathrm{sp}^{3}\right)$ bonds via transition metal-mediated cross-coupling reactions represents one of the most straightforward strategies for the introduction of difluoromethylene moieties $\left(C_{2} R, R \neq F, R_{f}\right)$ to aromatic compounds. This mini-review focuses on recent advances of this research topic from both synthetic and mechanistic perspectives.
\end{abstract}

Keywords: Arenes · Difluoromethylation - Difluoromethylene - Cross-coupling · Transition metal

\section{Introduction}

Fluorine-containing organic compounds have received considerable attention in various fields during the last few decades. ${ }^{[1]}$ This is largely due to the unique chemical, physical, and biological properties introduced by fluorine, and these compounds have found widespread applications in material chemistry, medicinal industry, and life sciences. ${ }^{[1 c]}$ We have witnessed the rapid growth in the development of novel synthetic methodologies for the incorporation of fluorine or fluorinecontaining moieties into organic molecules in recent years, among which, transition metal-mediated reactions play an important role because of the mild reaction conditions, diverse reaction formats, and high efficiency. [2]

The perfluoroalkylation (especially trifluoromethylation) of organic substrates involving transition metals have been extensively communicated and reviewed in past decades. ${ }^{[3]}$ However, the preparation of partially fluorinated compounds via fluoroalkylation has been far less developed although they are equally important as the perfluorinated ones in many fields. ${ }^{[4]}$ Aromatics with a difluoromethylene group ( $\mathrm{ArCF}_{2} \mathrm{R}, \mathrm{R} \neq \mathrm{F}, \mathrm{R}_{\mathrm{f}}$ ) are of significant utility. ${ }^{[5]}$ For instance, a difluoromethylene

${ }^{*}$ Correspondence: Prof. J. Hu

Key Laboratory of Organofluorine Chemistry

Shanghai Institute of Organic Chemistry,

Chinese Academy of Sciences

345 Ling-Ling Road, Shanghai 200032, China

E-mail: jinbohu@sioc.ac.cn motif $\left(\mathrm{CF}_{2}\right)$ can function as a bioisostere ${ }^{[6]}$ of oxygen with improved metabolic stability and oral bioavailability while the difluoromethyl group $\left(\mathrm{CF}_{2} \mathrm{H}\right)$ is regarded as a lipophilic hydrogen bond donor ${ }^{[7]}$ with excellent bioactivity. Recently, the synthesis of difluoromethylated arenes and derivatives assisted by transition metals has experienced a revival of interest. Inspired by the latest intriguing progress that has been achieved, we present a brief review on this topic from both synthetic and mechanistic perspectives.

\section{General Information}

Conventional methods for the preparation of difluoromethylene moieties include the deoxofluorination of the carbonyl group with sulfur tetrafluorides $\left(\mathrm{SF}_{4}\right), N, N$-diethylaminosulfur trifluoride (DAST) and its derivatives. ${ }^{[8]}$ The intrinsic limitations of these reagents, such as toxicity, narrow functional group-tolerance, and high cost, have restricted their widespread application. On the other hand, transition metal-mediated cross-coupling provides an alternative solution to the introduction of difluoromethylene moieties to arenes. Generally, there are three main categories of approaches that lead to carbon $\left(\mathrm{sp}^{2}\right)-$ carbon $\left(\mathrm{sp}^{3}\right)$ bond formation with transition metals: i) the reductive cross-coupling of two electrophiles with metal powder (Strategy A, Scheme 1), ii) the mediation of an electrophile with a nucleophile (Strategies B \& C, Scheme 1), and iii) the mainly oxidative coupling of two nucleophiles (Strategy D, Scheme 1). ${ }^{[2,9 b]}$ Copper, which is well-documented for promoting the Ullmann-type reaction, ${ }^{[9]}$ has been one of the most extensively employed metals in the cross-coupling reactions of the difluoromethylene motifs with aromatic groups via these four strategies. Recently, palladium and cobalt have also been studied that exhibit different reactivity relative to copper. All these metals $(\mathrm{Cu}, \mathrm{Pd}$, and $\mathrm{Co}$ ) will be discussed in Sections 3-5 respectively.

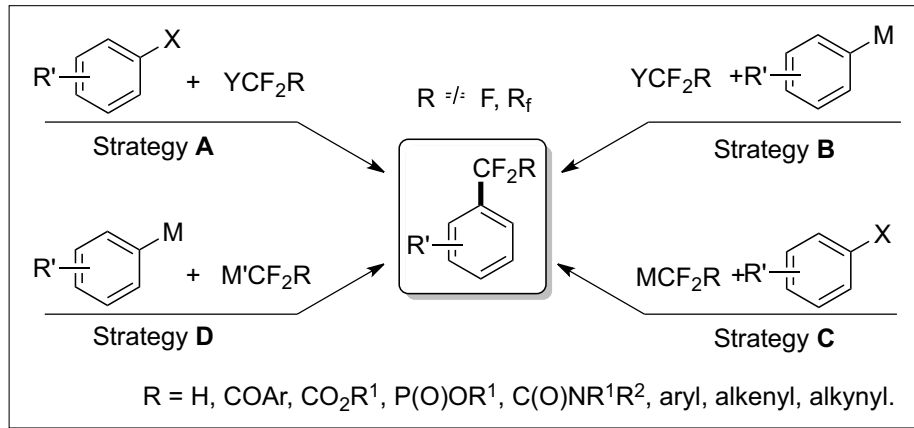

Scheme 1. Typical protocols for transition-metal-mediated difluoromethylenation reactions. 


\section{Copper-mediated Cross- coupling}

The coupling of perfluoroalkyl iodides with aryl halides in the presence of stoichiometric amounts of copper powder was first reported by McLoughlin et al. in 1969.[10] The reaction is believed to proceed via a ' $\mathrm{R}_{\mathrm{f}}-\mathrm{Cu}$ ' species as the key intermediate and has been widely applied in the perfluoroalkylation and trifluoromethylation of $\mathrm{sp}^{2}$ carbon thereafter. ${ }^{[3]}$ The corresponding aryl and alkenyl alkoxycarbonyldifluoromethylation with iododifluoroacetate $\left[\mathrm{ICF}_{2} \mathrm{CO}_{2} \mathrm{Me}\right]$ was reported by the Kobayashi group in 1986 (Scheme 2). ${ }^{[11 a]}$ The reaction of $\mathrm{ICF}_{2} \mathrm{CO}_{2} \mathrm{Me}$ with copper was found to be complete within 30-45 min in DMSO giving a relatively stable $\mathrm{ICuCF}_{2} \mathrm{CO}_{2} \mathrm{Me}$ species at room temperature. Reactions using aryl, alkenyl, alkyl, benzylic, and allylic iodides run smoothly at room temperature, but heating was needed for bromine electrophiles. It is noteworthy that even alkyl iodide could be converted with the assistance of HMPA. Moreover, this transformation was stereospecific for alkenyl iodides, which excluded the possibility of radical addition to double bond. In 2004, Sato et al. reinvestigated this reaction with bromodifluoroacetate $\left[\mathrm{BrCF}_{2} \mathrm{CO}_{2} \mathrm{Et}\right]{ }^{[11 \mathrm{~b}]}$ For aryl iodide substrates, moderate yields were obtained after reaction in DMSO for hours at $55^{\circ} \mathrm{C}$.

$\mathrm{Hu}$ and coworkers' investigations on the copper-mediated reaction between aryl iodide and iododifluoroacetamides revealed the coexistence of three types of transformations: cross-coupling, intramolecular cyclization, and homocoupling (Scheme 3). ${ }^{[12]}$ By tuning the substituents on the nitrogen atom, the selectivity was adjustable. A plausible mechanism was proposed based on their observations that implied the involvement of a single electron transfer (SET) process leading to the formation of ' $\mathrm{RCF}_{2}-\mathrm{Cu}$ '.

The Burton group ${ }^{[13 a]}$ and the Shibuya group ${ }^{[14 a]}$ found that the [(diethoxyphosphinyl)difluoromethyl]copper complex, obtained via the transmetallation of [(diethoxyphosphinyl)difluoromethyl] zinc bromide reagent with stoichiometric amounts of cuprous bromide $(\mathrm{CuBr})$, was unstable at room temperature and spontaneously decomposed within days. It should be noted that the decomposition process in DMF remarkably differs from that in monoglyme. In Burton's publication, the aryldifluoromethylated phosphonates were obtained by the cross-coupling of [(diethoxyphosphinyl)difluoromethyl] cadmium reagent with aryl iodides promoted by stoichiometric amounts of cuprous chloride $(\mathrm{CuCl}) .{ }^{[13 b]}$ This protocol exhibited excellent functional group tolerance, such as nitro, ester, and halides $(\mathrm{Br}$

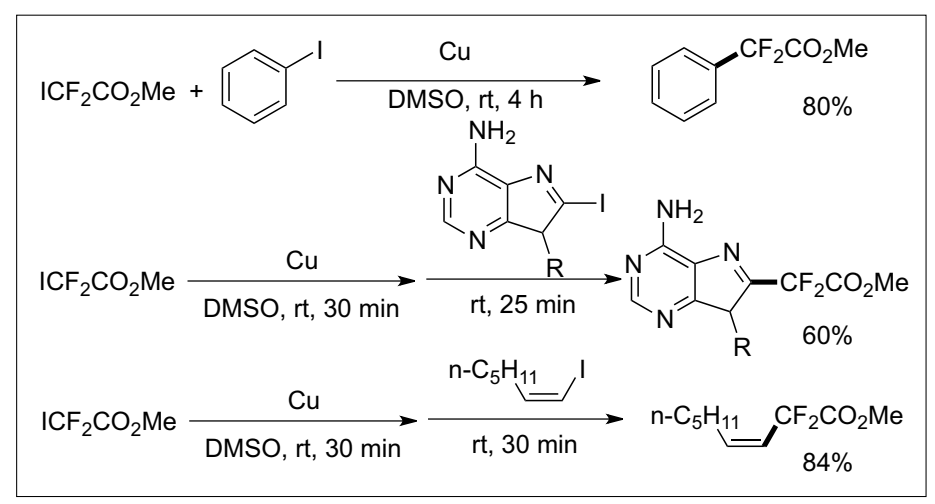

Scheme 2. Copperpowder-promoted alkoxycarbonyldifluoromethylenation of aryl and alkenyl iodides with iododifluoroacetate.

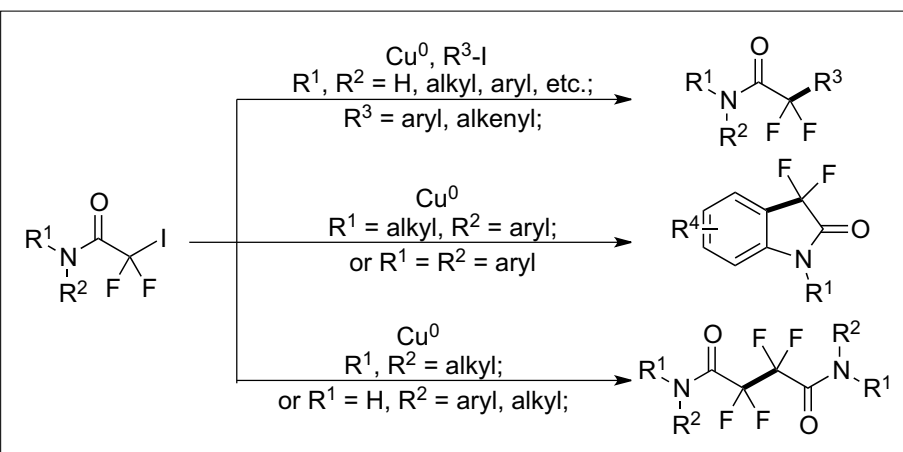

Scheme 3.

Controllable crosscoupling, intramolecular cyclization, and homocoupling reactions with iododifluoroacetamides. and $\mathrm{Cl}$ ) with high efficiency. Shibuya et al. developed a similar transformation with [(diethoxyphosphinyl)difluoromethyl] zinc reagent in place of the more toxic cadmium reagent. ${ }^{[14 b]}$ The reaction was conducted under the assistance of ultrasound and afforded lower output relative to the former case (Scheme 4).

Inspired by Shibuya's work, Zhang and coworkers realized the first catalytic version of copper-mediated cross-coupling of iodobenzoates with bromozincdifluorophosphonate (Scheme 5).[15] For substrates with an ortho-carboxylate ester as directing group, high efficiency and excellent functional group compatibilities were achieved. They declared that both ethereal solvent and catalytic amount of 1,10-phenanthroline are crucial to prevent the decomposition of the corresponding organocopper intermediate. Finally, the SET process was excluded and a plausible catalytic cycle involving $\mathrm{Cu}(\mathrm{III})$ was postulated on the basis of radical scavenging experi- ments. The concept of oxidative trifluoromethylation promoted by copper was first introduced by Qing and coworkers. ${ }^{[16 a]}$ Utilizing aromatic nucleophiles like boronic acid can broaden the scope of the cross-coupling reaction with diverse functional groups. Recently, they successfully applied this strategy to the cross-coupling of aryl boronic acid with $\alpha$-silyldifluoro methylphosphoonates. ${ }^{[16 \mathrm{~b}]}$ The substrate scope was good while the yield was moderate; however, stoichiometric amounts of both copper and silver salts were needed.

Difluoromethylated aromatic compounds have received significant interest for the design and development of bioactive agents. Preliminary studies from the Burton group indicated that the difluoromethylcopper species $\left(\mathrm{HCF}_{2} \mathrm{Cu}\right)$ lacks thermal stability above room temperature and decomposed rapidly to $\mathrm{HCF}_{2} \mathrm{CF}_{2} \mathrm{H}$ and cis- $\mathrm{CFH}=\mathrm{CFH} \cdot{ }^{[17]}$ Deriving from $\mathrm{HCF}_{2} \mathrm{Cd}$, such a $\mathrm{HCF}_{2} \mathrm{Cu}$ reagent reacted smoothly with electrophiles such as allylic, propar-

\begin{tabular}{|c|c|c|c|c|}
\hline Substrates & Reagents & Conditions & Products & Yield \\
\hline & $\begin{array}{l}(\mathrm{EtO})_{2} \mathrm{P}(\mathrm{O}) \mathrm{CF}_{2} \mathrm{CdX} \\
\quad(1.7 \text { equiv })\end{array}$ & $\begin{array}{c}\mathrm{CuCl} \text { (1.2 equiv), DMF } \\
\text { rt, } 3 \mathrm{~h}\end{array}$ & & $80 \%$ \\
\hline & $\begin{array}{l}(\mathrm{EtO})_{2} \mathrm{P}(\mathrm{O}) \mathrm{CF}_{2} \mathrm{ZnBr} \\
\text { (2.0 equiv) }\end{array}$ & $\begin{array}{l}\text { CuBr (2.0 equiv), DMA, } \\
\text { ultrasound, rt, } 24 \mathrm{~h}\end{array}$ & & $60 \%$ \\
\hline & $\begin{array}{l}(\mathrm{EtO})_{2} \mathrm{P}(\mathrm{O}) \mathrm{CF}_{2} \mathrm{CdX} \\
\quad(1.7 \text { equiv })\end{array}$ & $\begin{array}{c}\mathrm{CuCl} \text { (1.2 equiv), DMF } \\
\text { rt, } 3 \mathrm{~h}\end{array}$ & & $84 \%$ \\
\hline & $\begin{array}{c}(\mathrm{EtO})_{2} \mathrm{P}(\mathrm{O}) \mathrm{CF}_{2} \mathrm{ZnBr} \\
(2.0 \text { equiv })\end{array}$ & $\begin{array}{c}\text { CuBr (2.0 equiv), DMF } \\
\text { rt, } 15 \mathrm{~h}\end{array}$ & & $51 \%$ \\
\hline & $\begin{array}{c}(\mathrm{EtO})_{2} \mathrm{P}(\mathrm{O}) \mathrm{CF}_{2} \mathrm{CdX} \\
\text { (1.7 equiv) }\end{array}$ & $\begin{array}{c}\mathrm{CuCl} \text { (1.2 equiv), DMF } \\
\text { rt, } 3 \mathrm{~h}\end{array}$ & & $75 \%$ \\
\hline & $\begin{array}{c}(\mathrm{EtO})_{2} \mathrm{P}(\mathrm{O}) \mathrm{CF}_{2} \mathrm{ZnBr} \\
(2.0 \text { equiv })\end{array}$ & $\begin{array}{c}\text { CuBr (2.0 equiv), DMA } \\
\text { rt, } 24 \mathrm{~h}\end{array}$ & & $26 \%$ \\
\hline
\end{tabular}

Scheme 4. The difluoromethylenation of aryl iodides with [(diethoxyphosphinyl)difluoromethyl]metal reagents. 
gylic, alkynyl, and benzyl halides; however, the direct difluoromethylation of aromatic halides was not mentioned. Alternative approaches to difluoromethylated aromatic compounds involved two-step strategies: i) the introduction of a functionalized difluoromethylene group onto the aromatic ring, and ii) removing the functional group to afford the target molecules. Sulfone is a readily removable functionality and has been widely utilized in synthetic chemistry. ${ }^{[18]}$ In 2011, a (phenylsulfonyl)difluoromethylcopper $\left(\mathrm{PhSO}_{2} \mathrm{CF}_{2} \mathrm{Cu}\right)$ species was prepared by $\mathrm{Hu}$ et al..$^{[18 \mathrm{~b}]}$ However, this species possessed poor thermal stability and low reactivity similar to those of $\mathrm{HCF}_{2} \mathrm{Cu}$ and its coupling with aryl electrophiles was unsuccessful.

In 2011, Amii et al. described an efficient route leading to difluoromethylated aromatic compounds. ${ }^{[19]}$ The cross-coupling of aryl iodides with $\alpha$-silyldifluoroacetate (TMSCF $\mathrm{CO}_{2} \mathrm{Et}$ ) promoted by stoichiometric amount of cuprous iodide resulted in aryldifluoroacetates in high yields. These products were further hydrolyzed with the treatment of $\mathrm{K}_{2} \mathrm{CO}_{3} / \mathrm{MeOH} / \mathrm{H}_{2} \mathrm{O}$ followed by decarboxylation (KF/DMF, above $170{ }^{\circ} \mathrm{C}$ ) to release the difluoromethyl motif. Reagent $\mathrm{TMSCF}_{2} \mathrm{CO}_{2}$ Et is stable and readily accessible from trifluoroacetate. The catalytic version of the cross-coupling step was further demonstrated to give moderate yield by employing 20\% CuI (Scheme 6).

Recently, the Hartwig group and the Prakash group have independently made extraordinary breakthroughs in the field of copper-mediated direct difluoromethylation of aryl iodides with different difluoromethyl sources (Scheme 7). Fier and Hartwig ${ }^{[20 a]}$ reported that electron-rich aryl iodides could be difluoromethylated with 5.0 equiv of trimethylsilyl difluoromethane $\left(\mathrm{TMSCF}_{2} \mathrm{H}\right)$ and stoichiometric amount of $\mathrm{CuI}$ at $120^{\circ} \mathrm{C}$, while Prakash et al. ${ }^{[20 \mathrm{~b}]}$ found that both electron-deficient aryl and heteroaryl iodides could be difluoromethylated with no more than 3.0 equiv of tributyl(difluoromethyl)stannane and 1.3 equiv of $\mathrm{CuI}$ at $100-120^{\circ} \mathrm{C}$. According to Hartwig's experiments, either electron-deficient substrates or exogenous 1,10-phenanthroline ligands would result in hydrodehalogenation reaction. Since the $\mathrm{HCF}_{2} \mathrm{Cu}$ species was proved unstable and has not been observed, they tentatively provided a rationalization that $\left[\left(\mathrm{HCF}_{2}\right)_{2} \mathrm{Cu}\right]^{-}$acted as a stable reservoir for $\mathrm{HCF}_{2} \mathrm{Cu}$. The possibility of a radical process or $\mathrm{Cu}$ (III) intermediate was excluded, but further study on the mechanism is needed. On the basis of both theoretical calculations and experimental methods, Prakash and coworkers postulated $\mathrm{Cu}(\mathrm{III})$ as a key reactive intermediate, which differs from the former case.

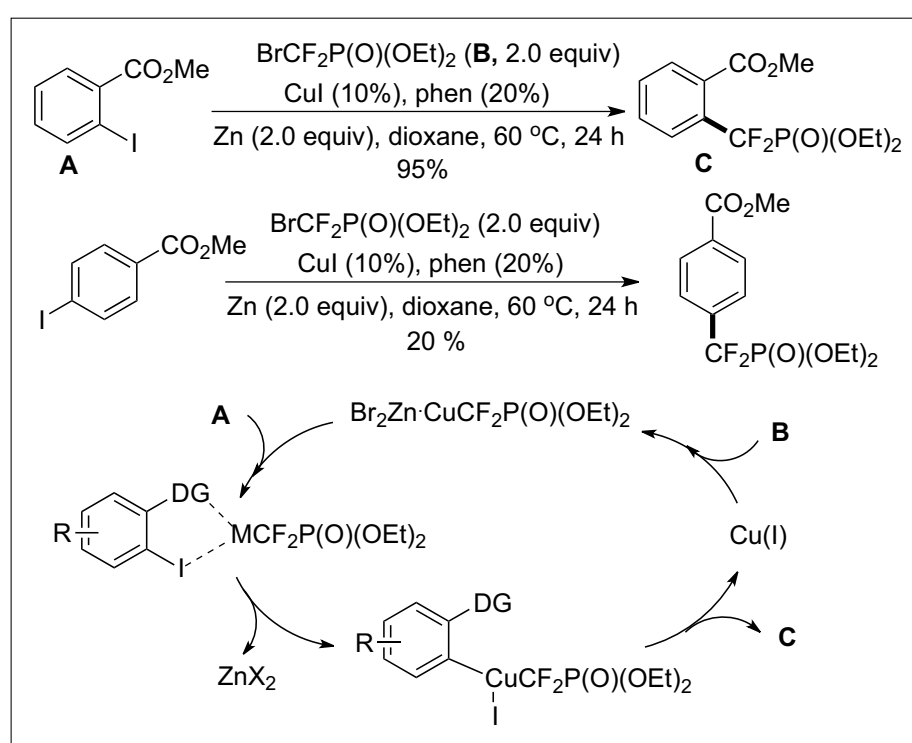

Scheme 5. Coppercatalyzed synthesis of aryldifluorophosphonates.

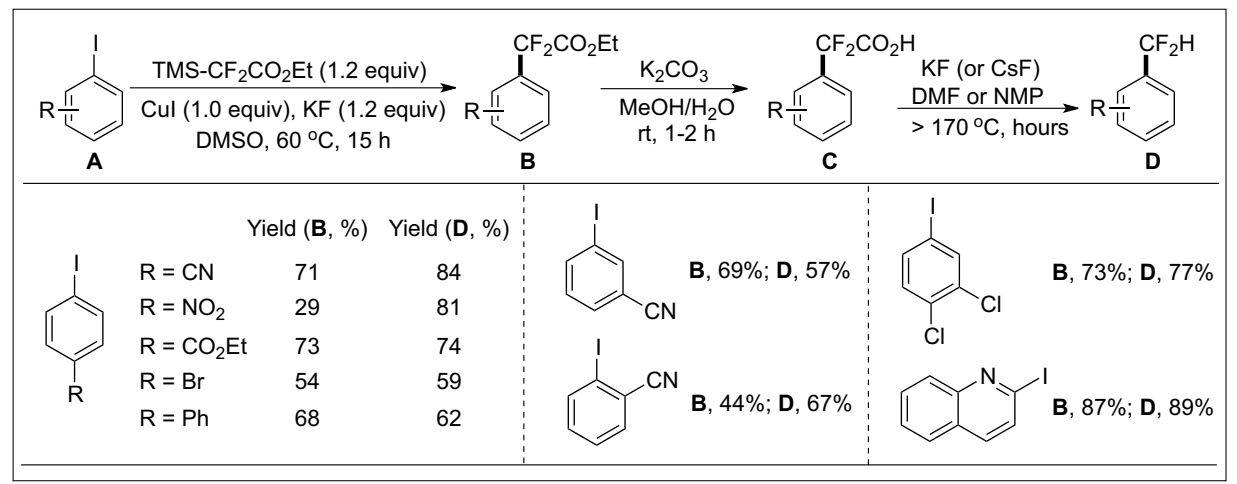

Scheme 6. A sequential copper-promoted multi-step synthesis of difluoromethylated arenes.

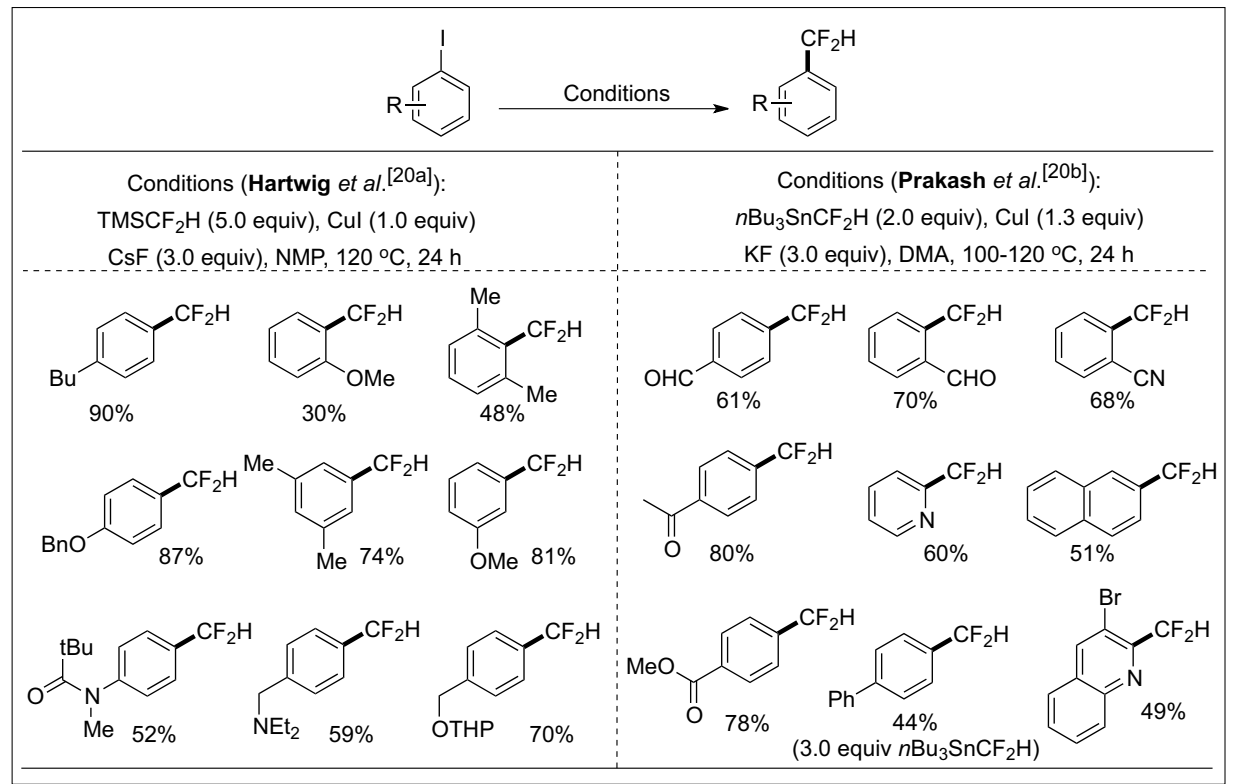

Scheme 7. Copper-mediated direct difluoromethylation of aryl iodides.

\section{Palladium-mediated Cross- coupling}

Generally, C-Pd(II) bond is more stable than the $\mathrm{C}-\mathrm{Cu}(\mathrm{I})$ bond and, as a consequence, less reactive. For instance, the trifluoromethylation of aryl iodides involving $\mathrm{CuCF}_{3}$ species undergoes smoothly even at room temperature while a similar transformation involving $\mathrm{Pd}(\mathrm{II}) \mathrm{CF}_{3}$ species must be assisted by bulky ligands. ${ }^{[21]}$ In this context, the palladium-promoted incorporation of the difluoromethylene motif into aromatics has not been fully investigated in recent years.

Magnesium-promoted selective defluorination of aryl trifluoromethyl ketones provide a straightforward approach to difluoroenol silyl ethers.[22] In 2007, Shreeve and Guo reported the first palla- 
dium-catalyzed cross-coupling reactions of difluoroenol silyl ethers with aryl bromide. ${ }^{[23]}$ Comparison of the relative reaction rate of substituted silyl enol ethers in Pd-catalyzed cross-coupling with bromobenzene indicated fluorine substitution did not significantly reduce the reactivity of silyl enol ethers. Such a base-free reaction exhibited excellent functional group compatibility such as cyano, nitro, ester, and carbonyl.

The involvement of toxic tributyltin fluoride retarded the wide application of Shreeve's method despite its efficiency and functional group compatibility. Based on Qing's results, Hartwig et al. recently reported a more general procedure for the synthesis of $\alpha$-aryl- $\alpha, \alpha$-difluoroketones by the palladium-catalyzed coupling of $\alpha, \alpha$-difluoroacetophenones with aryl halides (Scheme 8). ${ }^{[24 b]}$ For convenience, they prepared a single-component palladacyclic complex containing $\mathrm{P}(t-\mathrm{Bu})$ $\mathrm{Cy}_{2}$ as dative ligand. A range of functionalities were tolerated under these reaction conditions. It is noteworthy that both aryl bromide and aryl chloride could be efficiently transformed with low catalyst loading even in large scale. Intriguingly, the base-induced cleavage of the $\alpha$-aryl- $\alpha, \alpha$ difluoroketone products to give difluoromethylarene was observed. After further optimization, a one-pot procedure for the synthesis difluoromethylarene from $\alpha, \alpha$ difluoroacetophenones and aryl halides was realized. Since the second step was conducted with $\mathrm{KOH}$ in $\mathrm{H}_{2} \mathrm{O}$ at $100{ }^{\circ} \mathrm{C}$, the functional group compatibility was excellent. Ethers, thioethers, esters, ketones, carbamate moieties, amino groups, silyl groups and quinolone derivatives were tolerated with high overall yield.

As a continuing effort in the field of cross-coupling reaction with functionalized difluomethylene groups, Zhang et al. reported their recent study on the synthesis of aryldifluoromethylated phosphonates and carboxylic derivatives catalyzed by palladium (Scheme 9). $\left.{ }^{25 a}\right]$ Unlike the copper catalytic system with restricted substrate scope, the current reaction conditions were applicable to both bromodifluoromethylphosphonate and bromodifluoroacetate. To demonstrate its utility in medicinal chemistry, the authors applied their methodology to the synthesis of a protected protein phosphotyrosine phosphatase (PTPase) inhibitor and modification of a natural product. Radicalinhibition detection experiments suggested that a SET pathway via the difluoromethylenephosphonate radical may be involved in the catalytic cycle.

In 1995, the Shi group investigated the cross-coupling of nucleophiles with 1,1-difluoroallylpalladium complexes generated from 1,1-difluoroallyl acetates..26a]

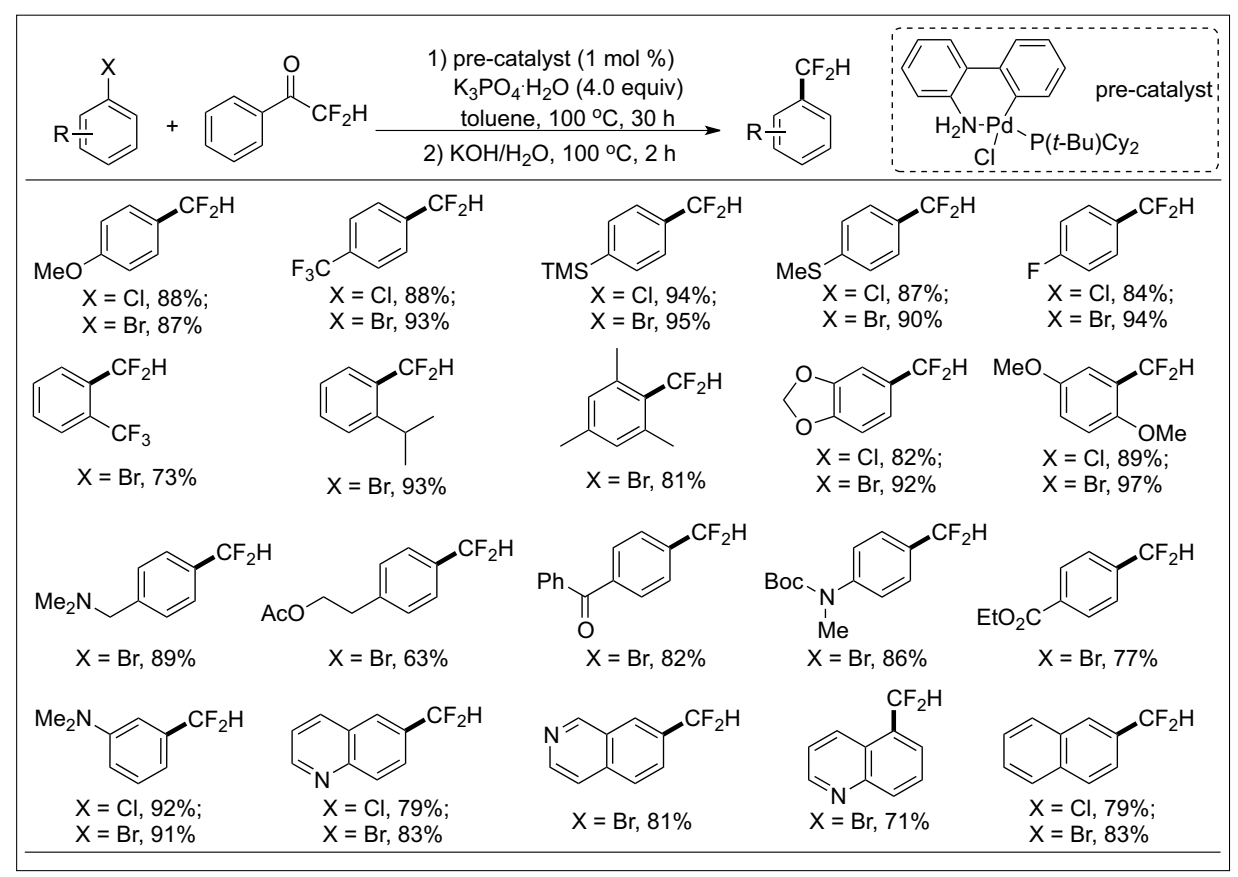

Scheme 8. Palladium-catalyzed preparation of $\alpha$-aryl- $\alpha, \alpha$-difluoroketones and their hydration to difluoromethylarenes.

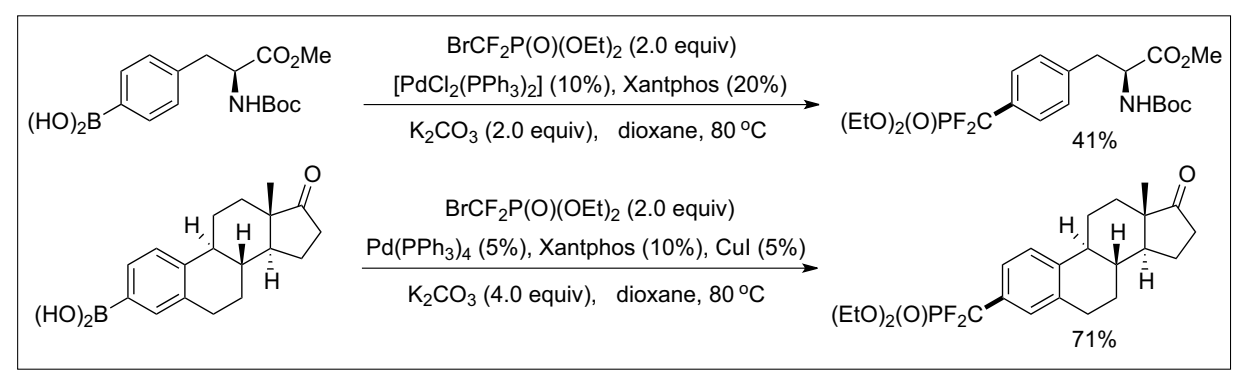

Scheme 9. Palladium-catalyzed difluoroalkylation of aryl boronic acids.
The Kirihara group also investigated the similar nucleophilic substitution by using 3-bromo-3,3-difluoropropene (BDFP) and its derivatives in the presence of palladium catalyst.[26b] These two groups' studies indicated that the regioselectivity ( $\alpha$ or $\gamma$ substituted product) has a direct relationship with both the hard-soft nature of the nucleophiles and the steric hindrances. In the latest report by Zhang, aryl borons were applied into the cross- coupling with BDFP (Scheme 10).[25b] This gem-difluoroallylation reaction exhibited excellent $\alpha / \gamma$ regioselectivity under mild reaction conditions. Catalyst loading could be reduced to $0.01 \%$ without significant loss of reactivity when the reaction was conducted on 10.0 gram scale. Arylboronic ester and aryl trifluoroborate salt were also examined under these reaction conditions and exhibited comparable reactivity. The synthetic application of this

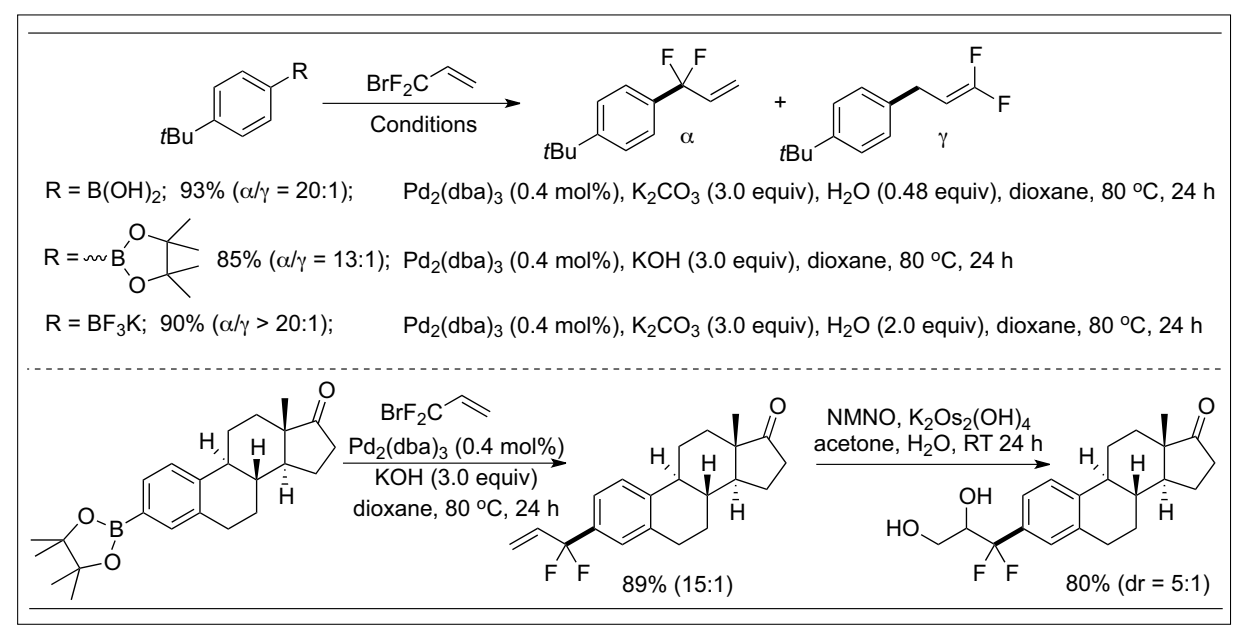

Scheme 10. Highly selective gem-difluoroallylation of organoborons with bromodifluoromethylated alkenes catalyzed by palladium. 
protocol was demonstrated with the gemfluoroallylation of bioactive natural products followed by further functionalization of the $\mathrm{C}-\mathrm{C}$ double bond.

Similar to that of the ' $\mathrm{RCF}_{2} \mathrm{Cu}(\mathrm{I})$ ' species $\left[\mathrm{R}=\mathrm{H}, \mathrm{C}(\mathrm{O}) \mathrm{Ar}, \mathrm{CO}_{2} \mathrm{Et}, \mathrm{C}(\mathrm{O}) \mathrm{NR}^{1} \mathrm{R}^{2}\right.$, $\mathrm{P}(\mathrm{O})(\mathrm{OEt})$, $\mathrm{SO} P \mathrm{Ph}]$, the substituents $\mathrm{R}$ have a subtle impact on the stability and reactivity of ' $\mathrm{RCF}_{2} \mathrm{Pd}(\mathrm{II})$ '. This kind of substitution effect can be crucial for the success of corresponding cross-coupling reactions. Although the cross-coupling of functionalized ' $\mathrm{RCF}_{2} \mathrm{Pd}(\mathrm{II})$ ' species $[\mathrm{R}=$ $\left.\mathrm{C}(\mathrm{O}) \mathrm{Ar}, \mathrm{CO}_{2} \mathrm{Et}, \mathrm{C}(\mathrm{O}) \mathrm{NR}^{1} \mathrm{R}^{2}, \mathrm{P}(\mathrm{O})(\mathrm{OEt})_{2}\right]$ with aryl substrates have been reported, the direct difluoromethylation and difluoroalkylation of arene derivatives involving ' $\mathrm{RCF}_{2} \mathrm{Pd}(\mathrm{II})$ ' ( $\mathrm{R}=\mathrm{H}$, alkyl) species is expected to be more challenging and has not yet been disclosed.

\section{Cobalt-mediated Cross-coupling}

Cobalt exhibits different reactivity in cross-coupling reactions relative to palladium, nickel, and copper. Typically, a SET mechanism is involved in the cobalt-catalyzed coupling of alkyl, alkenyl, and aryl halides with Grignard reagents or organozinc nucleophiles.[27] In 2013, Inoue and coworkers disclosed a cobaltcatalyzed cross-coupling reaction of arylzinc reagents with bromodifluoroacetate (Scheme 11).[28] Compared to the corresponding Grignard reagents that might cause the bromine-magnesium exchange background reaction, the TMEDA-ligated zinc nucleophiles were mild for manipulation giving acceptable yields with good tolerance of functionalities, such as bromine, chlorine, ester, methoxy, and methylthio groups.

\section{Conclusions and Perspectives}

There are two features that distinguish the chemistry of $\mathrm{RCF}_{2} \mathrm{M}\left(\mathrm{R} \neq \mathrm{F}, \mathrm{R}_{\mathrm{f}}\right)$ from that of $\mathrm{CF}_{3} \mathrm{M}$ : i) the $\mathrm{C}-\mathrm{M}$ bond in $\mathrm{RCF}_{2} \mathrm{M}$ is weaker than that of $\mathrm{CF}_{3} \mathrm{M}$. This trend has been confirmed by the reduced thermal stability of $\mathrm{RCF}_{2} \mathrm{Cu}$ species compared to $\mathrm{CF}_{3} \mathrm{Cu}$. ii) The substituents ' $\mathrm{R}$ ' play a crucial role in tuning the reactivity of $\mathrm{RCF}_{2} \mathrm{M}$ species, which is still not fully understood. These features make cross-coupling involving $\mathrm{RCF}_{2} \mathrm{M}$ species even more complicated. Transition metals currently involved

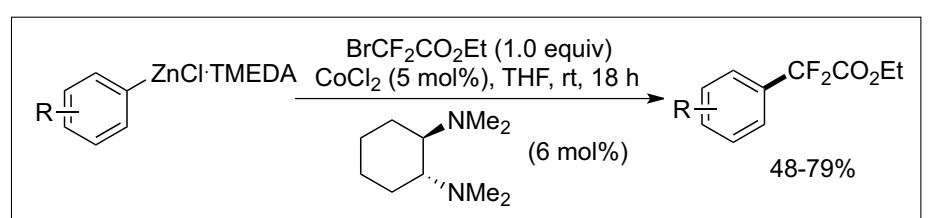
catalyzed alkoxycarbonyldifluoromethylation of arylzinc reagents with ethyl bromodifluoroacetate.

$\mathrm{R}=\mathrm{MeO}, \mathrm{CF}_{3}, \mathrm{Br}, \mathrm{Cl}, \mathrm{F}, \mathrm{PhO}, \mathrm{MeS},(\mathrm{EtO})_{2} \mathrm{CH} \ldots$

are restricted to copper and palladium while other environmentally benign sources like iron have not been examined. On the other hand, although other strategies including a radical process for the difluoromethylation methods for the incorporation of difluoromethylene building blocks to aromatics are far from common. With regard to electrophiles, the cheapest aryl chlorides are still unreactive in most reaction systems. Moreover, control of the site selectivity on the aromatic ring is another issue that must be addressed for an efficient transformation. Some of these cross-coupling reactions have been extended to other systems such alkenyl, alkynyl, allylic, benzylic, and propargyl halides. Further efforts for the incorporation of difluoromethylene motifs into alkyl terminals with transition metals would be another important aspect in synthetic chemistry. ${ }^{[30]}$

\section{Acknowledgements}

This work was supported by the National Basic Research Program of China (2012CB215500 and 2012CB821600), the National Natural Science Foundation of China (21372246 and 21202189), Shanghai QMX program (13QH1402400).

Received: March 30, 2014

1] a) R. D. Chambers, 'Fluorine in Organic Chemistry', Blackwell, Oxford, 2004; b) K. Uneyama, 'Organofluorine Chemistry', Blackwell, Oxford, 2006; c) P. Kirsch, 'Modern Fluoroorganic Chemistry: Synthesis, Reactivity, Applications', 2nd Ed., Wiley-VCH, Weinheim, 2013.

2] a) J. P. Collman, L. S. Hegedus, J. R. Norton, R. G. Finke, 'Principles and Applications of Organotransition Metal Chemistry', 2nd ed., University Science Books, Mill Valley, 1987; b) J. Hartwig, 'Organotransition Metal Chemistry: From Bond to Catalysis', University Science Books, Sausalito, California, 2010.

[3] For reviews, see: a) D. J. Burton, Z.-Y. Yang, Acc. Chem. Res. 2010, 43, 160; c) R. J. Lundgren, M. Stradiotto, Angew. Chem. Int. Ed. 2010, 49, 9322; d) M. A. Garcia-Monforte, Inorg. Chem. 2012, 2012, 4945; e) Y. Ye, M. S. Sanford, Synlett 2012, 23, 2005; f) J. Xu, X. Liu, Y. Fu, Tetrahedron Lett. 2014, 55, 585.

[4] a) J. S. Houlton, W. B. Motherwell, B. C. Ross, M. J. Tozer, D. J. Williams, A. M. Z. Slawin, Tetrahedron 1993, 49, 8087; b) S. Kaneko, T Yamazaki, T. Kitazume, J. Org. Chem. 1993, 58, 2302; c) W. F. Goure, K. L. Leschinsky, S. Wratten, J. P. Chupp, J. Agric. Food Chem. 1991, 39, 981

[5] a) M. J. Tozer, T. F. Herpin, Tetrahedron 1996, 52, 8619; b) G. Landelle, A. Panossian, S. of heteroarenes have also been reported, [29] 西

[28]

Pazenok, J.-P. Vors, F. R. Leroux, Beilstein J. Org. Chem. 2013, 9, 2476; c) Y. Zhao, C. Ni, F. Jiang, B. Gao, X. Shen, J. Hu, ACS Catal. 2013, 3, 631 .

[6] a) A. K. Yudin, G. K. S. Prakash, D. Deffieux, M. Bradley, R. Bau, G. A. Olah, J. Am. Chem. Soc. 1997, 119, 1572; b) N. A. Meanwell, $J$. Med. Chem. 2011, 54, 2529.

[7] J. A. Erickson, J. I. McLoughlin, J. Org. Chem. 1995, 60, 1626.

[8] a) G. A. Boswell, W. C. Ripka, R. M. Scriber, C. W. Tollock, Org. React. 1974, 21, 1; b) M. R. C. Gerstenberger, A. Haas, Angew. Chem. Int. Ed. 1981, 20, 647; c) W. J. Middleton, J. Org. Chem. 1975, 40, 574.

[9] a) F. Ullmann, J. Bielecki, Ber. 1901, 34, 2174; b) J. Hassan, M. Sévignon, C. Gozzi, E. Schulz, M. Lemaire, Chem. Rev. 2002, 102, 1359.

[10] V. C. R. McLoughlin, J. Thrower, Tetrahedron 1969, 25,5921

[11] a) T. Taguchi, O. Kitagawa, T. Morikawa, T. Nis hiwaki, H. Uehara, H. Endo, Y. Kobayashi, Tetrahedron Lett. 1986, 27, 6103; b) K. Sato, M. Omote, A. Ando, I. Kumadaki, J. Fluorine Chem. 2004, $125,509$.

[12] J. Zhu, W. Zhang, L. Zhang, J. Liu, J. Zheng, J. Hu, J. Org. Chem. 2010, 75, 5505

[13] a) L. G. Sprague, D. J. Burton, R. D. Guneratne, W. E. Bennett, J. Fluorine Chem. 1990, 49, 75; b) W. M. Qiu, D. J. Burton, Tetrahedron Lett. 1996, 37, 2745

[14] a) T. Yokomatsu, K. Suemune, T. Murano, S. Shibuya, J. Org. Chem. 1996, 6, 7207; b) T. Yokomatsu, T. Murano, K. Suemune, S. Shibuya, Tetrahedron 1997, 53, 815.

[15] Z. Feng, F. Chen, X. Zhang, Org. Lett. 2012, 14, 1938.

[16] a) L. Chu, F.-L. Qing, Org. Lett. 2012, 14, 2106; b) X. Jiang, L. Chu, F.-L. Qing, New J. Chem. 2013, 37, 1736.

[17] D. J. Burton, G. A. Hartgraves, J. Fluorine Chem. 2007, 128, 1198 .

[18] a) G. K. S. Prakash, J. Hu, Acc. Chem. Res. 2007, 40, 921; b) J. Zhu, F. Wang, W. Huang, Y. Zhao, W. Ye, J. Hu, Synlett 2011, 899.

[19] K. Fujikawa, Y. Fujioka, A. Kobayashi, H. Amii, Org. Lett. 2011, 13, 5560.

[20] a) P. S. Fier, J. F. Hartwig, J. Am. Chem. Soc 2012, 134, 5524; b) G. K. S. Prakash, S. K. Ganesh, J.-P. Jones, A. Kulkarni, K. Masood, J. K. Swabeck, G. A. Olah, Angew. Chem. Int. Ed. 2012, 51, 12090.

[21] a) V. V. Grushin, W. J. Marshall, J. Am. Chem. Soc. 2006, 128, 12644; b) E. J. Cho, T. D. Senecal, T. Kinzel, Y. Zhang, D. A. Watson, S. L. Buchwald, Science 2010, 328, 1679.

[22] H. Amii, T. Kobayashi, Y. Hatamoto, K. Uneyama, Chem. Commun. 1999, 1323.

[23] Y. Guo, J. M. Shreeve, Chem. Commun. 2007, 3583

[24] a) C. Guo, R.-W. Wang, F.-L. Qing, J. Fuorine Chem. 2012, 143, 135: B) S. Ge, W. Chaładaj, J. F. Hartwig, J. Am. Chem. Soc. 2014, 136, 4149.

[25] a) Z. Feng, Q.-Q. Min, Y.-L. Xiao, B. Zhang, X. Zhang, Angew. Chem. Int. Ed. 2014, 53, 1669; b) Q.-Q. Min, Z. Yin, Z. Feng, W.-H. Guo, X. Zhang, J. Am. Chem. Soc. 2014, 136, 1230.

[26] a) G.-Q. Shi, X.-H. Huang, F.-J. Zhang, Tetrahedron Lett. 1995, 36, 6305; b) M. Kirihara, T. Takuwa, M. Okumura, T. Wakikawa, H. Takahata, T. Momose, Y. Takeuchi, H. Nemoto, Chem. Pharm. Bull. 2000, 48, 885.

7] G. Cahiez, A. Moyeux, Chem. Rev. 2010, 110, 1435.

K. Araki, M. Inoue, Tetrahedron 2013, 69, 3913. D. Baxter, D. D. Dixon, M. R. Collins, D. G. Blackmond, P. S. Baran, J. Am. Chem. Soc. 2012, 134, 1494.

[30] V. V. Levin, A. A. Zemtsov, M. I. Struchkova, A. D. Dilman, Org. Lett. 2013, 15, 917. 